\title{
Japan reacts uneasily to nuclear plan for meeting carbon cuts
}

[TOKYO] Tension is growing in Japan over the latest detailed proposals to tackle global warming, which call for the active promotion of nuclear energy to help reduce the country's emissions of greenhouse gases.

The general policy outlines released last week by a task force on global warming, representing nine government ministries and agencies, are intended to provide specific measures for implementing Japan's commitment at last year's climate conference in Kyoto. Japan is committed to curbing emissions of greenhouse gases by 6 per cent from 1990 levels between 2008 and 2010 .

The proposals say that Japan's output of nuclear energy needs to be increased substantially to implement such a reduction, and that the total amount of electricity generated by nuclear power will need to grow by 50 per cent from its 1997 level by 2010.

But the electricity industry says that such an increase would be impossible, given the current antinuclear mood in Japan. According to officials at the Ministry of Trade and Industry (MITI), 20 nuclear reactors would have to be built to meet the targets.

Under the working group's proposals, Japan will aim to reduce emissions of carbon dioxide, nitrogen dioxide and methane by 2.5 per cent from 1990 levels by 2010, and to restrict the increase of emissions of hydrofluorocarbons, perfluorocarbons and sulphur hexafluoride to 2 per cent.

Although the government has previously raised the possibility of achieving a 3.7 per cent reduction by including 'sink gases' the amount of carbon dioxide absorbed by forests — the working group warns against relying on such a method. It argues that techniques for counting sink gases remain unproven, and that Japan will be expected to reduce its emissions by a further 3.7 per cent if such a method is adopted.

There is concern about the reliance on nuclear power because a series of accidents and subsequent cover-ups at nuclear facilities run by the Power Reactor and Nuclear Fuel Development Corporation (PNC) have led the public to lose confidence in Japan's nuclear policy (see Nature 386, 209; 1997).

"It would be extremely difficult to build more nuclear reactors in the current climate, considering how sensitive people are about nuclear safety," says a director at Tohoku Electric Power, which had to freeze its plans to build nuclear power reactors in Niigata Prefecture, in the north of Japan, in the face of strong opposition from local residents.

Tokyo Electric Power, one of the world's largest private electricity companies, faced

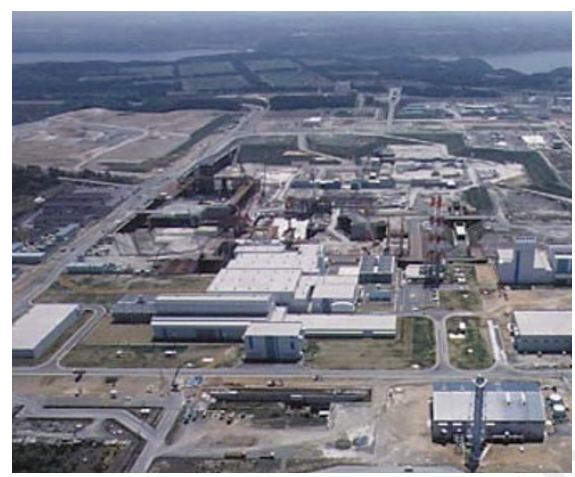

Waste not, want not: but nuclear facilities such as Rokkasho's reprocessing plant are out of favour.

similar problems when trying to build two reactors at its site in Fukushima, in northeast Japan. The company, which depends on nuclear energy for 40 per cent of its output, has no immediate plans to build more reactors; instead it will concentrate on improving the efficiency of its thermal power plants.

The electricity industry is facing several problems related to Japan's plans to curb the emission of greenhouse gases. For example, although it has projected a 50 per cent expansion in demand for power between 1990 and 2010, it is facing a target, set by MITI, to limit its increase in emissions to less than 20 per cent during that same period.

But the biggest hurdle so far is the plan to promote nuclear energy, which is unlikely to be implemented unless the central government agrees to give the industry its active support for such projects.

Mitsuo Horiuchi, the trade minister, said at a press conference last week that a major effort will be made to secure public acceptance of new nuclear power facilities, and that the question of radioactive waste disposal will be looked into urgently.

Another important task would be regaining public confidence. A white paper on nuclear energy issued last week by the Science and Technology Agency attributes public distrust in the government's nuclear policy to the discrepancy between 'technological safety' as seen by the experts and the 'sense of security' in the general public.

The report promises to restore the nation's trust in nuclear safety, and to endorse the importance of nuclear power as a future energy resource.

PNC, which is set to be transferred to a new semi-public organization in October, is likely be given responsibility for handling the issue of radioactive waste disposal, which it calculates is likely to start between 2030 and 2040.

AsakoSaegusa
[TOKYO] The International Thermonuclear Experimental Reactor (ITER), a proposed US $\$ 10$ billion project to build a next-generation fusion facility, faces significant scaling down after its council last week adopted new design parameters for a smaller, cheaper version.

At a meeting in Tokyo, council members of the ITER partners - the United States, Europe, Japan and Russia approved proposals by its working group to reduce costs by modifying some of its technical objectives.

The working group, set up in February to explore less expensive designs for the reactor, proposed in May that the cost could be cut by up to half by reducing the radius of the doughnutshaped confinement vessel from 8 metres to 6 metres (see Nature 393, 406; 1998), and by reducing its output from $1.5 \mathrm{GW}$ to $0.7 \mathrm{GW}$.

Although the new design would alleviate budgetary constraints, the reactor's ignition - required to generate a self-sustaining thermonuclear burn - is likely to be lost. But officials from the Japanese Atomic Energy Research Institute (JAERI), which put forward the plans for the scaled-down version, say that ignition may not be essential for carrying out successful nuclear fusion.

"Although some of ITER's aims have been relaxed, the proposed changes are not viewed as a compromise," says Hiroshi Kishimoto, an executive director.

Japan is the most likely candidate to host the site, as it is expected to put up the largest share of the cost for the international project.

At a meeting earlier this month, Japan's Atomic Energy Council decided to present ITER's design team with detailed data on Japan's regional characteristics, such as information on earthquake prevalence and maps of coastal areas adequate for placing fusion reactors.

Although it declined to look into sites, the council created a subcommittee on fusion energy development that will discuss Japan's future effort in nuclear-fusion research and the possibility of collaboration with industry. But the government says it will not make any decision about ITER's location for two years because of the nation's current economic crisis. A.s. 